\title{
Cardiac Compression during Initial Resuscitation
}

National Cancer Institute

\section{Source}

National Cancer Institute. Cardiac Compression during Initial Resuscitation. NCI

Thesaurus. Code C103157.

An emergency measure on newborns, which requires assistance to beg in breathing at birth. Initial resuscitation includes administration of positive-pressure ventilation and chest compressions to empty the ventricles of the heart in an effort to circulate the blood, and also to stimulate the heart so that it will resume its pumping action. 